\title{
Is the detection of hepatocellular carcinoma in liver transplantation candidates impaired using a dedicated CMR stress test as a 'one-stop-shop'? a pathological correlation study
}

\author{
Sahadev T Reddy*, Ngoc L Thai, Mark Doyle, Jose Oliva, Kususm B Tom, Rishi Maheshwary, June A Yamrozik, \\ Geetha Rayarao, Ronald B Williams, Moneal Shah, Jacqueline Poydence, Diane V Thompson, Robert W Biederman
}

From 17th Annual SCMR Scientific Sessions

New Orleans, LA, USA. 16-19 January 2014

\section{Background}

Precise diagnosis and staging of hepatocellular carcinoma (HCC) is crucial in the selection and timing of orthotopic liver transplantation (OLT) patients, especially cirrhotics. The preoperative workup of OLT patients is logistically cumbersome and expensive given the need for separate cardiac, vascular, and abdominal imaging. We have recently demonstrated the value of a 'one-stop-shop' approach combining the attributes of a nuclear stress, echocardiogram and abdominal MRI into one single preop CMR evaluation. However, this approach requires further validation as accurate detection of $\mathrm{HCC}$ is critically important. Hypothesis: HCC detectability is independent of whether the study is performed as part of a larger onestop-shop CMR or as a traditional focused MRI. Objective: We evaluated the 'detectability' of HCC using cardiac MRI for pre-operative evaluation of OLT candidates in a CMR suite performing assessment of cardiac structure, function and viability, along with simultaneous evaluation of thoracoabdominal vasculature and liver anatomy and compared with histopathology in explanted livers.

\section{Methods}

In this pilot study, patients $(\mathrm{n}=51)$ underwent a standard cardiac exam, stress CMR, and abdominal MRI on a dedicated CMR scanner during a single imaging session. Abdominal MRA along with liver parenchymal imaging was obtained via a Liver Acquisition with Volume Acquisition (LAVA) technique. Another representative cohort $(\mathrm{n}=26)$ underwent standard abdominal MRI in a

Cardiac MRI, Allegheny General Hospital, Pittsburgh, Pennsylvania, USA
Radiology Suite. Pathological results at explanations were compared to interpretation of the CMR/MRI exams.

\section{Results}

Over 3 years, 51/77 OLT candidates ( $56 \pm 5$ years, 35\% F, MELD score of 11; range 6-40) underwent MRI in a dedicated CMR suit as a part of an integrated pre-operative evaluation of liver and heart. The remaining 26 pts underwent traditional pre-op evaluation of liver while cardiac stress testing was performed elsewhere via nuclear/echo. All referred pts completed standard dynamic CMR, 98\% completed stress CMR, 94\% completed liver MRI and 45 pts $(88 \%)$ completing entire CMR exam. Nine pts $(20 \%)$ in the combined CMR group and $12(46 \%)$ in the traditional group proceeded to OLT. Of these, $2 / 9$ pts in the CMR group and 2/12 pts in the traditional group were found to have lesions suggestive of HCC. These findings were all confirmed at explant surgical pathology with $100 \%$ detection/exclusion for HCC (100\% NPV/PPV).

\section{Conclusions}

In this Proof-of-Concept study, it appears feasible to perform a comprehensive pre-operative liver transplant evaluation in a CMR suite for the detection of HCC lesions. Our study confirmed that MRI evaluation of the liver along with cardiac preoperative evaluation is equivalent to traditional testing for the detection of $\mathrm{HCC}$ lesions, which was confirmed with $100 \%$ histopathological concordance. This is an important next step towards validation of the CMR One-Stop-Shop concept for pre-op evaluation for potential OLT recipients. The final step is a cost-effective analysis. 
Table 1

\begin{tabular}{|c|c|c|}
\hline Patient Characteristics & $\begin{array}{c}n=51 \\
\text { (CMR Group) }\end{array}$ & $\begin{array}{c}n=26 \\
\text { (Traditional Group) }\end{array}$ \\
\hline Age (Mean \pm SD) & $56 \pm 8$ & $53 \pm 10$ \\
\hline Gender (Female \%) & $37 \%$ & $37 \%$ \\
\hline MELD score (Mean \pm SD; Range) & $11 \pm 8$; Range 6-40 & $22 \pm 10$; Range 6-40 \\
\hline Hepatic Encephalopathy (\%) & $39 \%$ & $39 \%$ \\
\hline Transplant Performed with stress test(\%) & $14 \%(9)$ & $46 \%(12)$ \\
\hline Transplant performed without stress test & $0 \%$ & $15 \%(4)$ \\
\hline Transplant patients with HCC on liver MRI & 2 & 2 \\
\hline HCC in explanted liver histopathology & 2 & 2 \\
\hline Critically III & $22 \%$ & $10 \%$ \\
\hline APACHE II Score & $22 \pm 7$ & $23 \pm 8$ \\
\hline $\begin{array}{l}\text { Etiology of Cirrhosis (\%) } \\
\text { 1. Cryptogenic/Unknown } \\
\text { 2. Alcohol } \\
\text { 3. NASH/NAFLD } \\
\text { 4. Hepatitis C } \\
\text { 5. Multiple Causes } \\
\text { 6. Hepatitis B } \\
\text { 7. Primary sclerosing cholangitis } \\
\text { 8. Primary biliary cirrhosis } \\
\text { 9. Cystic fibrosis } \\
\text { 10. Hemochromatosis }\end{array}$ & $\begin{array}{c}31 \% \\
25 \% \\
17 \% \\
13 \% \\
6 \% \\
4 \% \\
4 \% \\
2 \% \\
2 \%\end{array}$ & $\begin{array}{c}19 \% \\
12 \% \\
8 \% \\
22 \% \\
31 \% \\
4 \% \\
4 \% \\
2 \%\end{array}$ \\
\hline
\end{tabular}

Patient demographics and characteristics, Traditional group under went pre-evaluation without cardiac MRI (HCC- hepatocellular carcinoma; MELD - model for end-stage liver disease).

\section{Funding}

Internal.

Published: 16 January 2014

doi:10.1186/1532-429X-16-S1-P86

Cite this article as: Reddy et al:: Is the detection of hepatocellular

carcinoma in liver transplantation candidates impaired using a

dedicated CMR stress test as a 'one-stop-shop'? a pathological

correlation study. Journal of Cardiovascular Magnetic Resonance 201416

(Suppl 1):P86.

\section{Submit your next manuscript to BioMed Central} and take full advantage of:

- Convenient online submission

- Thorough peer review

- No space constraints or color figure charges

- Immediate publication on acceptance

- Inclusion in PubMed, CAS, Scopus and Google Scholar

- Research which is freely available for redistribution

Submit your manuscript at www.biomedcentral.com/submit
C Biomed Central 